\title{
Analisis Strategi Pengembangan Usaha Mebel Samawa di Kandai 2 Kecamatan Woja
}

\author{
Yeye Suhaety ${ }^{1}$, Mulyati², $^{2}$ Muhammad Fadillah ${ }^{3}$ \\ 1,2,3 Program studi Manajemen, STIE Yapis Dompu, Nusa Tenggara Barat, Indonesia \\ E-mail corresponding: yeyen.suhaety@gmail.com
}

Article History: Received: 2021-07-22 || Revised: 2021-07-28 || Published: 2021-08-31

Sejarah Artikel : Diterima: 2021-07-22 || Direvisi: 2021-07-28 || Dipublikasi: 2021-08-31

\begin{abstract}
The purpose of this study is to analyze the right business development strategy to be applied to Samawa furniture in Kandai 2, Woja sub-district. The data analysis used is SWOT analysis which consists of internal factors and external factors, while internal factors consist of strengths and weaknesses, while external factors consist of opportunities and weaknesses which have their own value. Based on the results of the study, it is known that the factors for developing the Samawa Furniture business consist of internal factors and external factors. the internal factors have a total score of 3.7 with a strength score of 2.4 and a weakness score of 1.3 . Meanwhile, external factors have a total score of 3.1 with an opportunity score of 1.6 and a threat score of 1.5 . After analyzing the data using the SWOT analysis technique, it can be concluded that the alternative strategy used for the development of the Samawa furniture business is using the SO strategy, where the strategy is in quadrant I which indicates that the position is very good for the development of the Samawa furniture business in the future. So that Samawa Furniture business can create a strategy that uses its strengths to take advantage of existing opportunities for the sustainability of the business.
\end{abstract}

Keywords: Strategy, Development, Business.

\begin{abstract}
Abstrak
Tujuan dari penelitian ini yaitu untuk menganalisis strategi pengembangan usaha yang tepat untuk diterapkan pada mebel samawa di kandai 2 kecamatan woja. Analisis data yang digunakan adalah Analisis SWOT yang dimana terdiri dari faktor internal dan faktor eksternal, adapun faktor internal terdiri dari kekuatan (strength) dan kelemahan (weakness) sedangkan faktor eksternal terdiri dari peluang (opportunities) dan kelemahan (threats) yang memiliki nilai tersendiri. Berdasarkan hasil penelitian diketahui bahwa faktor-faktor pengembangan usaha Mebel Samawa yang terdiri dari faktor internal dan faktor eksternal. adapun faktor internal memiliki total nilai sebesar 3,7 dengan skor kekuatan 2,4 dan skor kelemahan 1,3. Sedangkan untuk faktor eksternal memiliki total nilai sebesar 3,1 dengan skor peluang 1,6 dan skor ancaman 1,5. setelah melakukan analisis data dengan menggunakan tehknik analisis SWOT, maka dapat disimpulkan bahwa alternatif strategi yang digunakan untuk pengembangan usaha mebel Samawa yaitu dengan menggunakan strategi So, dimana strategi tersebut berada pada kuadran I yang menunjukkan bahwa posisi tersebut sangat baik untuk perkembangan usaha mebel samawa kedepannya, Sehingga usaha Mebel samawa dapat menciptakan strategi yang menggunakan kekuatan yang dimiliki untuk memanfaatkan peluang yang ada untuk kebelangsungan jalannya usaha.
\end{abstract}

Kata kunci: Strategi, Pengembangan, Usaha.

\section{PENDAHULUAN}

Industri mebel atau furniture adalah industri perlengkapan rumah yang mencakup semua barang seperti kursi, meja, dipan, pintu, jendela dan lemari. Mebel berasal dari kata movable, yang artinya bisa bergerak. Pada zaman dahulu meja, kursi, lemari dan lain sebagainya relatif mudah digerakkan dari batu besar, tembok, dan atap, sedangkan kata furniture berasal dari bahasa Prancis fourniture (1520-30 Masehi). Fourniture mempunyai asal kata furnish yang artinya perabot rumah atau ruangan. Walaupun meubel dan furniture punya arti yang beda, tetapi yang ditunjuk sama yaitu meja, kursi, lemari, dan perlengkapan pendukung lainnya. Mebel bukan hanya bermanfaat untuk kenyamanan dan kerapian rumah saja tetapi juga mengusung makna-makna sosial yang menegaskan status sosial. 
Perencanaan strategi dalam usaha sangatlah penting dibutuhkan karena strategi adalah arah yang akan dijalani untuk memulai sebuah usaha. Sebelum seseorang mendirikan usaha harus merencanakan dan memperhitungkan dengan cermat bagaimana biaya yang akan ditanggung untuk mendirikan usaha, pekerja yang ahli sesuai bidangnya, alat produksi yang digunakan dan sebagainya. Untuk memperoleh hasil produksi yang bagus dan tidak memerlukan biaya yang terlalu besar, maka sangatlah diperlukan perencanaan yang benar, Industri Mebel di Kabupaten Dompu itu tergolong usaha kecil menengah yang menjadi salah satu sumber kekuatan ekonomi lokal yang mendukung peningkatan pendapatan Domestik Bruto yang pada gilirannya menjadi salahsatu usaha kecil menengah yang mampu mendukung peningkatan perekonomian dan kesejahteraan masyarakat khususnya di Kabupaten Dompu.

Mebel Samawa termasuk dalam kategori usaha mebel yang baru tumbuh dan tentunya akan didapati sejumlah masalah dalam perjalannya seperti terbatasnya sarana penunjang proses produksi seperti alat alat produksi, ketatnya persaingan, kurangnya fasilitas yang akan menunjang promosi dan distribusi barang dan tentunya akan berdampak pada pengembangan usaha mebel samawa kandai 2, Dimana perbulannya mebel samawa hanya mampu menjual sekitar 12 barang dengan jenis yang berbeda dan akan sangat membutuhkan daya dukung untuk mampu bertahan dan berkembang lebih baik. Daya dukung utama bagi mebel samawa adalah strategi pengembangan bisnis seperti modal(financial) yang besar, dan sumberdaya manusia yang profesional. Dalam upaya meningkatkan kemampuan bersaing dengan usaha mebel lainnya, Mebel samawa mulai mengembangkan strategi pemasaran yaitu membangun komunikasi dengan konsumen untuk menginformasikan produk sekaligus menarik minat konsumen terhadap produk mebel yang dibuat, memilih lokasi usaha yang dekat dengan konsumen dan mudah dijangkau.

Menjalankan suatu usaha tentunya mempunyai tujuan agar tetap mampu berkembang dan bersaing dengan kompetitornya sehingga penjualan perbulannya dapat meningkat yang sebelumya mebel samawa hanya mampu menjual sebanyak 12 barang diharapkan kedepannya meningkat dan pendapatan diharapkan selalu bertambah. Hal ini tidak terlepas dari pentingnya peran strategi bisnis yang diterapkan oleh setiap lini usaha termasuk pada mebel samawa, Persaingan dalam dunia usaha menuntut pelaku bisnis untuk dapat membuat dan merancang sebuah strategi yang akurat dan tepat sasaran.

\section{METODE PENELITIAN}

Jenis penelitian ini adalah penelitian kualitatif deskriptif, yaitu data yang di kumpulkan berbentuk kata-kata, gambar, bukan angka-angka. Menurut bogdan dan taylor dalam moleong (2000: 3), penelitian kualitatif adalah prosedur penelitian yang menghasilkan data deskriptif berupa katakata tertulis atau lisan dari orang-orang dan perilaku yang diamati. Sementara itu, menurut moleong (2000: 17), penelitian deskriptif adalah suatu bentuk penelitian yang di tujukan untuk mendeskripsikan atau menggambarkan fenomena-fenomena yang ada, baik fenomena alamiah maupun rekayasa manusia. Adapun tujuan dari penelitian deskriptif adalah untuk membuat gambaran peneliti secara sistematis, faktual, dan akurat mengenai fakta dan strategi pemasaran dalam meningkatkan daya saing pada industri produk mebel di Kecamatan. Woja Kabupaten Dompu, Penelitian ini di lakukan di Kecamatan Woja Kabupaten Dompu karena di kecamatan ini terdapat beberapa industri Mebel Kayu Jati yang potensial salah satunya Mebel Samawa, adapun alasan memilih lokasi penelitian tersebut yaitu karna pada lokasi tersebut terdapat pengusahapengusaha Mebel yang saling bersaing dengan mebel lainnya untuk meningkatkan pendapatan di tunjang dengan kondisi wilayah yang tidak sulit di jangkau dan informasi data usaha Meubel yang cukup tersedia. Dan yang menjadi pertimbangan lain yaitu industri Mebel Samawa juga mempunyai usaha yang potensial, karena produk yang di hasilkan bagus, unik dan kreatif dengan ukiran jati yang mewah, namun terkendala dalam memasarkan produknya, Untuk menganalisis data dalam penelitian ini peneliti menggunakan analasis "SWOT" yang merupakan salah satu analisis sesuai dengan penelitian ini. Sedangakan untuk mendapatkan data yang benar dan pasti, maka peneliti melakukan pengecakan keabsahan data hasil penelitian dengan trianggulasi data. 
III. HASIL DAN PEMBAHASAN

\section{A. Analisis Data}

Analisis data yang digunakan dalam penelitian ini yaitu analisis SWOT. Analisis SWOT digunakan untuk membuat suatu strategi dalam peningkatkan produksi Usaha Pada Mebel Samawa Di Kandai 2 Kec. Woja Kab. Dompu. Tahap pengumpulan data analisis SWOT dapat dibedakan menjadi dua yaitu data internal strengths, weaknesses dan eksternal oprtunities, treats (Rangkuti, 2003).

\section{Analisis Faktor Internal}

Berdasarkan hasil penelitian pada responden Usaha Mebel Samawa Kandai 2 Kecamatan Woja Kabupten Dompu. Diperoleh faktor-faktor internal kekuatan dan kelemahan yang mempengaruhi pengembangan Usaha Mebel Samawa Kandai 2 yang terlihat pada Tabel berikut ini:

Tabel 1. Analisis SWOT Matriks IFAS Pada Usaha Mebel Samawa Kandai 2

\begin{tabular}{|c|c|c|c|}
\hline Faktor Internal & Bobot & Rating & $\begin{array}{c}\text { Skor Pembobotan } \\
\text { (Bobot x Rating) }\end{array}$ \\
\hline \multicolumn{4}{|l|}{ Kekuatan (Strengths) } \\
\hline 1. Peralatan penunjang produksi & 0,20 & 4 & 0,8 \\
\hline 2. Pemasaran & 0,10 & 3 & 0,3 \\
\hline $\begin{array}{l}\text { 3. Sumber daya yang } \\
\text { berkompeten }\end{array}$ & 0,20 & 4 & 0,8 \\
\hline \multirow[t]{2}{*}{ 4. Bahan baku berkualitas } & 0,10 & 5 & 0,5 \\
\hline & & & 2,4 \\
\hline \multicolumn{4}{|l|}{ Kelemahan (Weaknesses) } \\
\hline $\begin{array}{l}\text { 1. Daerah pemasaran yang } \\
\text { kurang luas (Dompu) }\end{array}$ & 0,10 & 3 & 0,3 \\
\hline 2. Lamanya proses bahan baku & 0,20 & 3 & 0,6 \\
\hline \multirow[t]{2}{*}{$\begin{array}{l}\text { 3. Kesulitan mendapatkan } \\
\text { pekerja (SDM) }\end{array}$} & 0,10 & 4 & 0,4 \\
\hline & 1,00 & & 1,3 \\
\hline TOTAL & & & 3,7 \\
\hline
\end{tabular}

Tabel diatas menjelaskan bahwa faktor internal memiliki kekuatan terbesar adalah peralatan penunjang produksi dengan skor pembobotan 0,8 dan yang memiliki skor pembobotan terendah adalah pemasaran dengan bobot skor sebesar 0,3. Lamanya proses bahan baku menjadi faktor kelemahan dengan bobot tertinggi yakni sebesar 0,6 sedangkan daerah pemasaran yang kurang luas (Dompu) menjadi faktor kelemahan dengan bobot yang paling rendah sebesar 0,3.

\section{Analisis Faktor Eksternal}

Berdasarkan hasil penelitian pada responden Mebel Samawa diperoleh faktor-faktor eksternal peluang dan ancaman yang akan dapat mempengaruhi pengembangan Mebel samawa yang terlihat pada Tabel berikut ini:

Tabel 2. Analisis SWOT Matriks EFAS Usaha Pada Mebel Samawa Kandai 2

\begin{tabular}{lccc}
\hline \multicolumn{1}{c}{ Faktor Eksternal } & Bobot & Rating & $\begin{array}{c}\text { Skor Pembobotan } \\
\text { (Bobot x Rating) }\end{array}$ \\
\hline \multicolumn{1}{c}{ Peluang (Opportunity) } & & & 0,6 \\
\hline 1. Pemanfaatan dari teknologi & 0,20 & 3 & 0,8 \\
\hline $\begin{array}{c}\text { 2. Minat konsumen akan } \\
\text { perabotan semakin tinggi }\end{array}$ & 0,20 & 4 & 0,2 \\
\hline $\begin{array}{c}\text { 3. Menjalin kerja sama dengan } \\
\text { perusahaan lain }\end{array}$ & 0,10 & 2 & $\mathbf{1 , 6}$ \\
\hline \multicolumn{1}{c}{ Ancaman (Treats) } & & & 0,8 \\
\hline 1. Munculnya pesaing yang & 0,20 & 4 & \\
\hline
\end{tabular}




\begin{tabular}{llll}
\hline \multicolumn{2}{c}{ bergerak di usaha mebel } & & \\
\hline 2. Harga bahan baku tidak stabil & 0,10 & 3 & 0,3 \\
\hline 3. Faktor cuaca & 0,20 & 2 & 0,4 \\
\hline & $\mathbf{1 , 0 0}$ & & $\mathbf{1 , 5}$ \\
\hline \multicolumn{2}{c}{ TOTAL } & & $\mathbf{3 , 1}$ \\
\hline
\end{tabular}

Diatas diatas menjelaskan bahwa faktor eksternal yang memiliki peluang tertinggi adalah minat konsumen akan perabotan semakin tinggi dengan bobot 0,8 dan yang memiliki skor bobot teren dah adalah menjalin kerja sama dengan perusahaan lain dengan bobot 0,2. Sedangkan dari faktor ancaman bobot tertinggi ada pada munculnya pesaing yang bergerak di usaha mebel dengan bobot 0,8 dan faktor eksternal yang memiliki skor pembobotan terendah dari ancaman adalah harga bahan baku tidak stabil dengan bobot 0,3 .

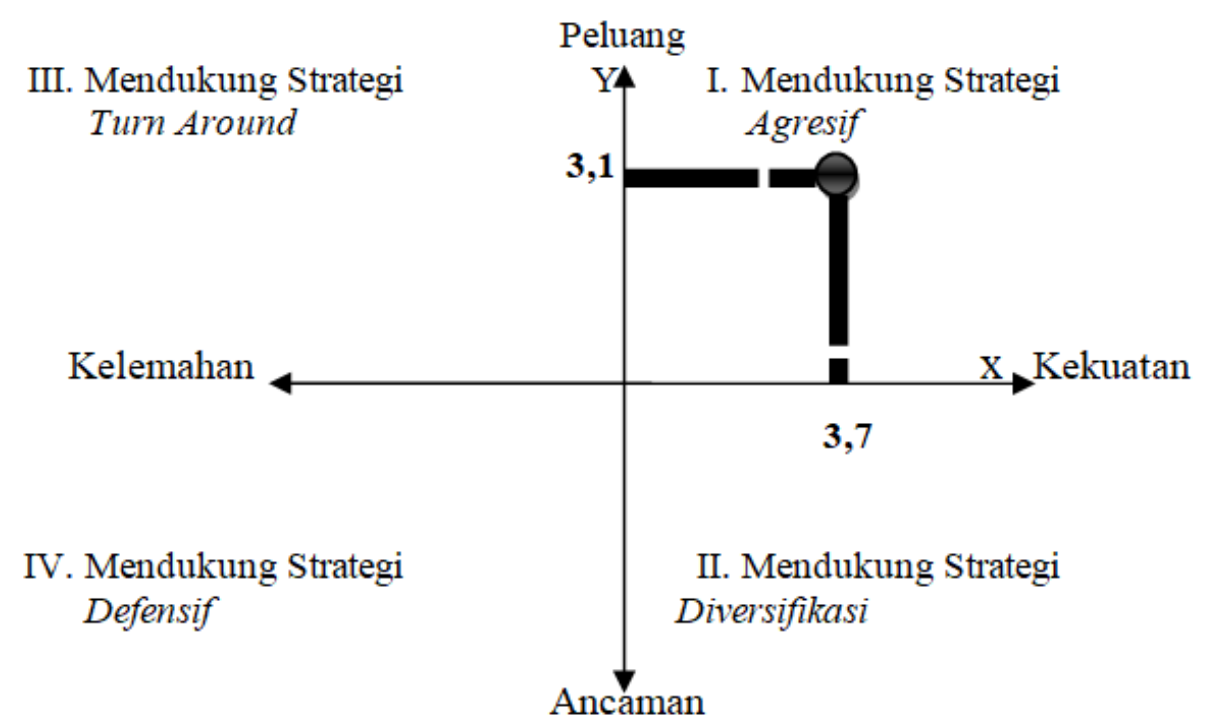

Gambar 1. Diagram Analisis SWOT

Berdasarkan hasil dari diagram analisis SWOT titik potongnya berada pada X,Y $(3,7 ; 3,1)$ berada pada diagram 1 dimana posisi tersebut merupakan situasi yang saangat menguntungkan. Mebel samawa Kandai 2 memiliki peluang dan kekuatan sehingga dapat memanfaatkan peluang yang ada. Strategi yang harus diterapkan dalam kondisi ini adalah mendukung kebijakan pertumbuhan yang agresif,

Berdasarkan diagram analisis SWOT pada gambar diatas menunjukan bahwa, posisi untuk strategi pengembangan Usaha Mebel samawa berada pada kuadran I, dimana situasi ini sangat menguntungkan pada posisi ini sebuah usaha maupun industri memiliki posisi yang kuat dan berpeluang untuk berkembang. Selanjutnya strategi yang perlu ditempuh adalah strategi pertumbuhan cepat (rapid growth strategy) yang berarti bahwa industri ini mempunyai kemampuan untuk mengisi peluang pasar dari bidang usahanya yang sekarang dengan memilih cara yang tercepat karena secara selektif tersedia sumber daya, agar peluang yang ada tidak jatuh ketangan pesaing. Demikian strategi ideal yang harus ditempuh diantaranya mengembangkan staf untuk bisa merancang pesanan pelanggan walaupun tanpa contoh dan meningkatkan kualitas produksi.

\section{B. Alternatif Strategi yang digunakan untuk Pengembangan Usaha Mebel Samawa}

Berdasarkan hasil analisis lingkungan faktor internal dan faktor eksternal pada Industri Mebel Samawa Kandai 2, maka dapat menggunakan pendekatan matriks SWOT untuk mengetahui alternatif strategi apa yang tepat digunakan agar usaha tersebut dapat berkembang lebih baik lagi. 
Tabel 3. Analisis Matriks SWOT

\begin{tabular}{|c|c|c|}
\hline IFAS & $\begin{array}{l}\text { WEAKNESS }(\boldsymbol{W}) \\
\text { 1. Daerah pemasaran yang } \\
\text { kurang luas (Dompu) } \\
\text { 2. Lamanya proses bahan baku } \\
\text { 3. Kesulitan mendapatkan } \\
\text { pekerja (SDM) }\end{array}$ & $\begin{array}{l}\quad \text { STRENGTH }(\boldsymbol{S}) \\
\text { 1. bahan Baku Berkualitas } \\
\text { 2. Peralatan penunjang produksi } \\
\text { 3. Sumber daya yang } \\
\text { berkompeten } \\
\text { Pemasaran }\end{array}$ \\
\hline \multicolumn{3}{|l|}{ EFAS } \\
\hline $\begin{array}{l}\text { OPPORTUNITY }(\boldsymbol{O}) \\
\text { 1. Pemanfaatan dari } \\
\text { teknologi } \\
\text { 2. Minat konsumen akan } \\
\text { perabotan semakin } \\
\text { tinggi } \\
\text { 3. Menjalin kerja sama } \\
\text { dengan perusahaan } \\
\text { lain }\end{array}$ & \begin{tabular}{l}
\multicolumn{1}{c}{ STRATEGI WO } \\
1. Memperluas jaringan usaha \\
dengan bekerja sama dengan \\
industri mebel dari jawa \\
untuk mendatangkan barang \\
yang serupa namun dengan \\
harga lebih murah \\
2. Untuk mengantisipasi \\
lamanya proses bahan baku \\
yang lama maka alternatifnya \\
harus membeli bahan baku \\
yang jadi agar proses \\
produksi bisa berjalan dan \\
juga bisa memesan barang \\
jadi yang yang sesuai \\
keinginan konsumen
\end{tabular} & \begin{tabular}{l}
\multicolumn{1}{c}{ STRATEGI SO } \\
1. Dengan peralatan yang \\
memadai akan mempermudah \\
proses produksi dan desain \\
yang diinginkan \\
2. Dengan tingginya minat \\
konsumen terhadap perabotan \\
rumah maka dari itu harus \\
berinovasi terhadap model \\
model barang \\
3. Memperluas jaringan kerja \\
sama dengan perusahaan lain \\
seperti tokoh-tokoh mebel \\
yang ada untuk mensuplay \\
barang
\end{tabular} \\
\hline $\begin{array}{l}\text { THREAT (T) } \\
\text { 1. Munculnya pesaing } \\
\text { yang bergerak di usaha } \\
\text { mebel } \\
\text { 2. Harga bahan baku } \\
\text { tidak stabil } \\
\text { 3. Faktor cuaca }\end{array}$ & \begin{tabular}{l}
\multicolumn{1}{c}{ STRATEGI WT } \\
1. Memperkuat promosi secara \\
online maupun offline untuk \\
memperbesar wilayah \\
pemasaran serta \\
memberikan pelayanan yang \\
maksimal guna \\
memenangkan persaingan \\
2. Memberikan pelayanan yang \\
lebih kepada setiap \\
pelanggan guna timbul \\
kepuasan bagi para \\
konsumen
\end{tabular} & $\begin{array}{l}\text { STRATEGI ST } \\
\text { 1. Menciptakan inovasi terhadap } \\
\text { setiap desain barang dari } \\
\text { bentuknya ataupun warnanya } \\
\text { 2. Mencari jaringan penjualan } \\
\text { bahan baku yang lebih murah, } \\
\text { baik secara online maupun } \\
\text { offline } \\
\text { 3. Mengantisipasi cuaca yang } \\
\text { sedang tidak bersahabat } \\
\text { dengan menyiapkan tempat } \\
\text { dan peralatan yang dapat } \\
\text { membantu meminimalisir } \\
\text { resiko yang ditimbulkan oleh } \\
\text { perubahan cuaca }\end{array}$ \\
\hline
\end{tabular}

Berdasarkan analisis matriks SWOT, dapat diterapkan beberapa strategi alternatif yang mendukung pengembangan Usaha Mebel Samawa Kandai 2 sebagai berikut:

STRATEGI SO:

1. Dengan peralatan yang memadai akan mempermudah proses produksi dan desain yang diinginkan yang tentunya akan member nilai tambah bagi mebel samawa sehingga dapat memproduksi sesuai dengan permintaan dari konsumen.

2. Dengan tingginya minat konsumen terhadap perabotan rumah maka dari itu harus berinovasi terhadap model model barang dengan menghadirkan model yang terbaru yang belum pernah ada, sehingga kedepannya konsumen akan semakin melirik produk produk di mebel samawa

3. Memperluas jaringan kerja sama dengan perusahaan lain seperti toko-toko mebel yang ada untuk menyuplai barang sehingga permintaan barang produksi mebel samawa semakin meningkat dan tersebar luas tentunya ini menjadi kesempatan bagus perkembangannya kedepan. 
STRATEGI WO:

1. Memperluas jaringan usaha dengan bekerja sama dengan industri mebel dari jawa untuk mendatangkan barang yang serupa namun dengan harga lebih murah, ini menjadi salah satu cara yang harus dilakukan oleh mebel samawa dalam agar kebutuhan kebutuhan akan suatu barang itu terpenuhi.

2. Untuk mengantisipasi lamanya proses bahan baku yang lama maka alternatifnya harus membeli bahan baku yang jadi agar proses produksi bisa berjalan cepat dan juga bisa memesan barang jadi yang sesuai pesanan konsumen sehingga tidak memerlukan waktu yang lama agar barang konsumen diselesaikan dengan tepat waktu.

\section{STRATEGI ST:}

1. Menciptakan inovasi terhadap setiap desain barang dari bentuknya ataupun warnanya, mengingat tungginya persaingan antara mebel yang ada dikabupaten dompu maka dari itu dengan kelengkapan peralatan yang memadai mebel samawa harus mampu memberikan sesuatu yang lebih terhadap konsumen sehingga konsumen tidak melirik ke mebel lain karena telah mendapatkan kepuasan dari konsumen.

2. Mencari jaringan penjualan bahan baku yang lebih murah, baik secara online maupun offline, dengan modal dan keuntungan yang dimiliki mebel samawa harus menyetok bahan baku sebanyak banyak sebagai persiapan bahan baku produksi.

3. Mengantisipasi cuaca yang sedang tidak bersahabat dengan menyiapkan tempat dan peralatan yang dapat membantu meminimalisir resiko yang ditimbulkan oleh perubahan cuaca, dengan begitu aktivitas produksi akan tetap berjalan meskipun ditengah cuaca yang sedang buruk.

\section{STRATEGI WT:}

1. Memperkuat promosi secara online maupun offline untuk memperbesar wilayah pemasaran serta memberikan pelayanan yang maksimal guna memenangkan persaingan,merekrut tenaga kerja baru yang dijadikan sebagai mitra kerja dalam hal pemasaran.

2. Memberikan pelayanan yang lebih kepada setiap pelanggan guna timbul kepuasan bagi para konsumen sehingga konsumen akan terus berlangganan dan memesan barang pada mebel samawa, kemudian juga memberikan kemudahan bagi konsumen dengan pembayaran secara kredit, dan juga berbagai macam bonus bagi pelanggan setia mebel samawa.

\section{SIMPULAN DAN SARAN}

\section{A. Simpulan}

Berdasarkan hasil analisis SWOT, menunjukan bahwa mebel samawa berada pada kuadran I, hal ini menunjukan mebel samawa memiliki kondisi internal (kekuatan) dan eksternal ( peluang) yang kuat. Sehingga mebel samawa berfokus pada strategi "SO"

\section{B. Saran}

Agar Mebel Samawa dapat mendukung strategi agresif maka dapat menerapkan startegi SO yaitu:

1. Dengan peralatan yang memadai akan mempermudah proses produksi dan desain yang diinginkan yang tentunya akan member nilai tambah bagi mebel samawa sehingga mebel samawa dapat memproduksi sesuai dengan permintaan dari konsumen.

2. Dengan tingginya minat konsumen terhadap perabotan rumah maka dari itu harus berinovasi terhadap model model barang dengan menghadirkan model yang terbaru yang belum pernah ada sebelumnya, sehingga kedepannya konsumen akan semakin melirik produk produk di mebel samawa

3. Memperluas jaringan kerja sama dengan perusahaan lain seperti toko-toko mebel yang ada untuk menyuplai barang sehingga permintaan barang produksi mebel samawa semakin meningkat dan tersebar luas tentunya ini menjadi kesempatan bagus perkembangannya kedepan.

\section{DAFTAR RUJUKAN}

Allison, M., dan Kaye, J. 2004. Perencanaan Strategis Bagi Organisasi Nirlaba. Jakarta: Yayasan Obor Indonesia 
Anita Kustiarini dan dhiah fitrayani. 2004. Strategi pengembangan UKM batu arca di desa watesumpak dalam menghadapi globalisasi. E-joernal UNESA.vol 2.no 3

Arikunto, S (2002). Prosedur penelitian, suatu pendekatan praktek. Jakarta: PT Rineka Cipta.

David, F R. 2004. Manajemen Strategis Konsep-Konsep. PT. Indeks Kelompok Gramedia. Jakarta.

David, Fred R. 2006. Manajemen Strategis. Edisi 10. Jakarta: Salemba Empat

Heri susanto (2016) strategi pengembangan UMKM pelaku ekonomi kreatif subsector kerajinan dan fesyen di daerah istimewa Yogyakarta.

Hunger, J. David and Thomas L Wheelen. 2003. Manajemen Strategis.Penerbit Andi. Yogyakarta.

Jatmiko, Rahmad Dwi. 2003. Manajemen Stratejik. Malang : UMM Press

Kotler \& keller. 2009. manajemen pemasaran. jilid I. edisi ke 13. jakarta: erlangga

Makmur, saprijal. 2015. strategi. 2015. strategi pemasaran dalam meningkatkan volume penjualan.jurnal ilmiah caro ekonomi vol. 3, No. 1 januari.

Meleong Lexy J. 2004, Metodologi Penelitian Kualitatif, Bandung: Remaja. Rosdakarya.

Moleong, Lexy J 2000. Metodologi penelitian kualitatif. Bandung: PT. Remaja Rosdakarya.

Muhammad regalfa M (2015)strategi pengembangan usaha kecil dan menengah melalui marketing online oleh dinas koperasi dan UMKM kabupaten banyuwangi.

Pearce II, John A. dan Robinson Richard B.Jr. (2008). Manajemen Strategis 10. Salemba Empat : Jakarta

Purhantara, Wahyu. 2010. Metode penelitian kualitatif untuk bisnis Yogyakarta: Graha ilmu.

Purhantara, Wahyu. 2010. Metode penelitian kualitatif untuk bisnis Yogyakarta: Graha ilmu.

Rangkuti, Freddy. 2006. Analisis SWOT Teknik Membedah Kasus Bisnis. Jakarta: PT. Gramedia Pustaka Utama.

Singarimbun, Masri dan sofian Effendi, 2002. Metode penelitian survai. Jakarta: LP3ES.

Sugiyono, (2008). Metode penelitian kuantitatif kualitatif dan R\&D. Bandung Alfabeta.

Tjiptono, Fandy. 2008. Stretegi Pemasaran. Edisi III.Yogyakarta: CV. Andi Offset

Wheelen, Thomas L dan Hunger, J. David .(2012). Manajemen Strategis. Yogyakarta: Andi 